Research Article

\title{
Phytochemical Composition and Biological Activity of Faidherbia albida (Mimosaceae) Roots and Leaves
}

\author{
Tchebemou Bakang Bruno ${ }^{1}$, Soh Désiré2 ${ }^{2}$ Nkwengoua Tchouboun Zondegoumba Ernestine ${ }^{1 *}$, Nganso Ditchou Yves \\ Oscar $^{3}$, Emmanuel Mouafo Tekwu ${ }^{4}$, Kerstin Andrea-Marobela ${ }^{5}$, Nyasse Barthélemy ${ }^{1 *}$ \\ ${ }^{1}$ Department of Organic Chemistry, Faculty of Science, University of Yaoundé I, Box 812 Yaoundé, Cameroon. \\ 2 Department of Chemistry, Higher Teacher Training College, University of Bamenda, PO Box 39 Bambili, Cameroon /TWAS Research Unit (TRU) of \\ The University of Bamenda, Bamenda, Cameroon. \\ ${ }^{3}$ Department of Chemistry, Faculty of Science, University of Maroua, P.O Box 814, Maroua, Cameroon. \\ 4Laboratory of Tuberculosis Research and Pharmacology, Biotechnology Centre, Nkolbisson, University of Yaoundé 1, Yaoundé, Cameroon. \\ ${ }^{5}$ Department of Biological Sciences University of Botswana Block 235/Room 251 Private Bag 0022 Gaborone Botswana. \\ *Corresponding author's E-mail: ernestine.nkweng@gmail.com
}

Received: 05-08-2020; Revised: 18-10-2020; Accepted: 26-10-2020; Published on: 15-11-2020.

\section{ABSTRACT}

Phytochemical composition of roots and leaves of Faidherbia albida, let to the isolation and the identification of fourteen (14) compounds namely $3 \beta$-Friedelinol (1), Friedelan-3-one (2), Heptadecanoic acid (3), Ergosterol- $\beta$-D-glucoside (4), (3R,4R,5S,6R)-2(hydroxymethyl)-6-(4,4a,6b,8a,11,11,12b,14a-octamethyl-docosahydropicen-3-yloxy)-tetrahydro-2H-pyran-3,4,5-triol Brassicasterol Benzoate (6), Lupeol (7), Betulin (8), Oleanolic acid (9), Maslinic acid (10), Apigenin (11) Kaempferol (12)], Quercetin-3$\mathrm{O}-\alpha$ - rhamnoside (13) and Trans-Tiliroside (14). The structures of all the isolated constituents were determined by a comprehensive use of spectroscopic analysis such as 1D- and 2D-NMR, EI-MS, and ESI-MS coupled with the comparison of data thereof obtained with those of known analogs listed in the literature. These compounds and various extracts, fractions were investigated for their antioxidant potential, and antischistosomal and antifungal effects against Schistosoma mansoni and Candida albicans respectively, $\alpha$ Glucosidal and Trypsin activity. The results revealed that all the extracts (roots and leaves), exhibited antifungal, antioxidant and enzyme $\alpha$-Glucosidase inhibition activities. Moreover, Quercetin-3-O- $\alpha$ - rhamnoside (13) inhibited $\alpha$-Glucosidase, Trypsin and Schistosoma mansoni. The synergic effect of the extract and fraction, and also their triple of Quercetin-3-0- $\alpha$ - rhamnoside (13) could classified Faidherbia albida among the potential candidate for the development of multitarget drugs. This could reduce the combination of multiple biological active agent (multitherapy) therapy in favor of multitarget drug strategies.

Keywords: Faidherbia albida, Quercetin-3-O- $\alpha$ - rhamnoside, $\alpha$-Glucosidase inhibition, Trypsin inhibition, Anti-cercaricidal activity, Multitarget drugs.

QUICK RESPONSE CODE $\rightarrow$

DOI:

10.47583/ijpsrr.2020.v65i01.018

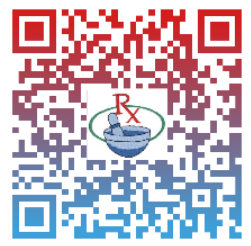

DOI link: http://dx.doi.org/10.47583/ijpsrr.2020.v65i01.018

\section{INTRODUCTION}

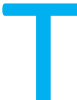

his work is a follow up of our previous efforts on the study of medicinal plants of Africa in general and in particular of the chemical constituents of Dissotis perkinsiae (Melastomaceae) so as to promote sources of compounds with potential antimicrobial activities ${ }^{1}$. These research axe could be explored in the development of new the new therapeutic natural product, which corrobores with the assumption that more than $60 \%$ of the African population make use of their traditional medicine with more implication of the medicinal plants ${ }^{2}$. The special interest on Faidherbia albida ${ }^{3}$, also known as Acacia albida $^{4}$, a plant of Mimosaceae/Leguminosacae/Fabaceae family is based on the fact that the species grows in more arid zones, which confers its with anti-stress ability and a capacity to fix nitrogen, water and other useful nutrients from deep soils ${ }^{5-8}$. The bark and leaves extracts are prescribed in traditional medicine to treat respiratory infections, fertility disorders, and digestive ailments, backache, malaria, etc ${ }^{9-12}$. Moreover in vitro qualitative phytochemical studies shown this plant possess a great quantity of triterpenes, sterols, glycosides, and tannins ${ }^{13-}$ 14. Pharmacological studies have indicated antiinflammatory, anti trypanosomal, antidiabetic, antimalarial, antifungal, Neumaticidal activities of their bark crude bark extracts ${ }^{14-21}$, providing scientific resources for their indigenous use. Previous phytochemical studies indicated that the seeds and fruits essential oil of were rich in fatty acids ${ }^{22}$ and the GC-MS analysis of essential oils from the stem bark revealed the presence of 37 different constituents of which $\alpha$-pinene was the major one $e^{22}$. In addition, the extraction and characterization of the fruits of the plant revealed the presence non polar constituents such as of stearic acid, oleic acid, linoleic acid, methyl ester and linolenic acid, methyl ester ${ }^{23}$. In our knowledge, there is unreported literature on their roots and leaves. The chemotaxanomic and ethnopharmacological significance 
of the genus Faidherbia prompted us to investigate the secondary metabolites of Faidherbia albida. Thus, this work reports on the isolation and identification of 14 constituents isolated from the leaves and roots of Faidherbia albida and on the biological activities observed on some extracts and isolated secondary metabolites.

\section{MATERIALS AND METHODS}

\section{General experimental procedures}

Mass spectroscopic data [Electrospray ionization mass spectrometry (ESI-MS)] were measured on a Waters Synapt HDMS spectrometer. NMR spectra were recorded with a Varian spectrometer at $400 \mathrm{MHz}$. Chemical shifts $(\delta)$ were quoted in parts per million (ppm) from the internal standard tetramethylsilane (TMS). Deuterated solvents dimethyl sulfoxide (DMSO-d6), and chloroform $\left(\mathrm{CDCl}_{3}\right)$ were used as solvents for the NMR experiments. Column chromatography was performed on silica gel 60 [(0.2-0.5 $\mathrm{mm}$ ) and (0.2-0.063 mm)] mesh (Sigma-Aldrich, Germany). Pre-coated silica gel 60 F254 thin layer chromatography (TLC) plates (Merck, Germany) were used for monitoring fractions and spots were detected with UV light (254 and $365 \mathrm{~nm})$ and then sprayed with $30 \%$ sulphuric acid $\left(\mathrm{H}_{2} \mathrm{SO}_{4}\right)$ followed by heating to $110^{\circ} \mathrm{C}$.

\section{Collection of Plant and Preparation}

Roots and leaves of Faidherbia albida were collected in Maroua-Cameroon, (June, 2013) by Dr Frumsia (Plant taxonomist) and identified at the Cameroon National Herbarium (HNC), where a voucher specimens $N^{\circ} 58978$ /SRF/Cam are deposited.

\section{Extraction and isolation of Faidherbia albida roots and leaves}

The roots and leaves were dried at room temperature and powdered. 1500g of powdered roots were extracted by maceration in 07 liters (7I) of dichloromethane/methanol (DCM/MeOH, 1:1, v/v) mixture at room temperature for 72 h. The filtrate was concentrated in rotavapor (Büchi R-200) under reduced pressure at $65^{\circ} \mathrm{C}$ to yield $240 \mathrm{~g}$ of extract. The crude material was dissolved in water and successively extracted with hexane, dichloromethane, ethyl acetate and $n$-butanol. All these extracts collected were preserved for chemical analysis.

Hexane fraction (14.3 g) was subjected to vacuum liquid chromatography (VLC) over silica gel grade (GF254) eluted with $n$-hexane/ethyle acetate (AcOEt) mixture with increasing polarity from $n$-hexane to AcOEt. Eight fractions (F1-F8) were obtained after combining subfractions according to their TLC profiles. Fraction F1 was subjected to column chromatography with $\mathrm{n}$-hexane/AcOEt gradient mixtures to yield 36 -friedelinol $(9.15 \mathrm{mg})$. Fraction F2 obtained at a polarity of $n$-hexane/AcOEt (85:15), friedelan-3-one (5.05 mg), heptadecanoic acid (4.64 mg). Fraction F8 obtained with n-hexane/AcOEt (20:80) was subjected to other column chromatography with $n$ hexane/AcOEt increasing polarity to yield Ergosterol-B-Dglucoside (7.26 mg).
The ethyl acetate fraction was subjected to column chromatography (CC) over silica gel $(4 \times 150 \mathrm{~cm}, 250 \mathrm{~g}$, 70 - 230 mesh) and eluted with $n$-hexane: AcOEt mixture with increasing polarity to afford 96 subfractions combined in five fractions (F1-F5) according to their TLC profiles. Fraction F2 was subjected to other column chromatography to yield (3R,4R,5S,6R)-2(hydroxymethyl)-6-(4,4a,6b,8a,11,11,12b,14aoctamethyl-docosahydropicen-3-yloxy)-tetrahydro-2Hpyran-3,4,5-triol (6.27 mg) and Brassicasterol Benzoate (7.12 mg). Fraction F4 was subjected to column chromatography (CC) and eluted with $n$-hexane/AcOEt mixture with increasing polarity to yield Kaempferol (6.14 $\mathrm{mg}$ ) and Trans-Tiliroside (9.16 mg) (Table 1).

$1240 \mathrm{~g}$ of powdered leaves were extracted by maceration in seven liters (5I) of dichloromethane/methanol (DCM/ methanol $(\mathrm{MeOH}), 1: 1, \mathrm{v} / \mathrm{v}$ ) mixture at room temperature for $72 \mathrm{~h}$. The filtrate was concentrated in rotavapor (Büchi $\mathrm{R}-200)$ under reduce pressure at $65^{\circ} \mathrm{C}$ to yield $143 \mathrm{~g}$ of extract. Dried extract was dissolved in water and successively extracted with hexane, dichloromethane, ethyl acetate and n-butanol. All these extracts collected were preserved for chemical analysis.

Hexane fraction (21.6 g) was subjected to vacuum liquid chromatography (VLC) over silica gel (GF254) and eluted with $n$-hexane/AcOEt mixture with increasing polarity from $n$-hexane to AcOEt. Four fractions (F1-F4) were obtained after combining subfractions according to their TLC profiles. Fraction F1 was subjected to column chromatography with $\mathrm{n}$-hexane/AcOEt gradient mixtures to yield Lupeol (4.16 mg), Betulin (3.25 mg). Fraction F2 obtained at a polarity of n-hexane/AcOEt (85:15), yield Maslinic acid $(7.15 \mathrm{mg})$ and Oleanolic acid $(5.20 \mathrm{mg})$. Fraction F4 obtained with n-hexane/AcOEt (20:80) was subjected to other column chromatography with $n$ hexane/AcOEt increasing polarity to yield Ergosterol- $\beta-D$ glucoside $(3.26 \mathrm{mg})$. The ethyl acetate soluble fraction was subjected to column chromatography (CC) over silica gel $(4 \times 150 \mathrm{~cm}, 250 \mathrm{~g}, 70-230 \mathrm{mesh})$ and eluted with $n$ hexane: AcOEt mixture with increasing polarity to afford 66 subfractions combined in six fractions (F1-F6) according to their TLC profiles. Fraction F2 was subjected to other column chromatography to yield Kaempferol (4.02 mg), Quercetin-3-O- $\alpha$ - rhamnoside (3.17 mg), Apigenin (2.10 $\mathrm{mg}$ ). Fraction F3 was subjected to column chromatography (CC) and eluted with $n$-hexane/AcOEt mixture with increasing polarity to yield Trans-Tiliroside (5.13 mg).

\section{Preparation of stock solution of plants crude extracts, fractions and compounds}

The different stock solution of plant, fractions and compounds were prepared by dissolving $2 \mathrm{mg}$ in $1 \mathrm{ml}$ of DMSO $10 \%$ for a final concentration of $2 \mathrm{mg} / \mathrm{ml}$. Reference antibiotics were prepared in the same condition by dissolving $512 \mathrm{mg}$ of Fluconazole (Sigma Aldrich) and $2 \mathrm{mg}$ of Chloramphenicol and Ampicillin (Sigma Aldrich) in $1 \mathrm{ml}$ of DMSO $10 \%$ to yield $512 \mu \mathrm{g} / \mathrm{ml}$ and $2 \mathrm{mg} / \mathrm{ml}$ respectively. After preparation, the different stock solutions were

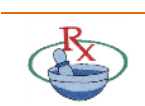


sterilized with $0.20 \mu \mathrm{M}$ Syringe Filter and store at $-20^{\circ} \mathrm{C}$ before use.

\section{Antioxidant assay}

A sample of $20 \mathrm{ml}$ of potassium persulphate $(50 \mathrm{mg} / \mathrm{ml})$ was added to the $1 \mathrm{ml}$ of azino-bisethylbenzothiazolinesulphonic acid diammonium salt (ABTS, Fluka, Switzerland). The mixture was incubated for $1 \mathrm{~h}$ at room temperature until persulphate had oxidized ABTS to a green-black coloured product. The oxidized ABTS stock solution was then diluted 1:10 in distilled water and $200 \mathrm{ml}$ of diluted working solution was pipetted into each well of a 96 well-microtiter plate. A solution of $60 \%$ ethanol in water was used as a negative control and ascorbic acid (1 $\mathrm{mM}$ ) was used as appositive control. An amount of $10 \mathrm{ml}$ of controls or compounds was added to duplicate wells of the plate and stirred gently using the pipette tip. Antioxidant activity was recorded for compounds which reduced $A B T S$ from green to colourless.

\section{$\alpha$-Glucosidase and Trypsin Inhibition \&Activity Assay Starch}

Agar plates were prepared by boiling agar ( $10 \mathrm{~g} / \mathrm{lHi}$ Media) with potato starch $(15 \mathrm{~g} / \mathrm{l})$ in distilled water. The mixture was poured into petri dishes (Falcon) to solidify. $\alpha$ Glucosidase was Isolated from 4-day old pea shoots by grinding fresh shoots with phosphate buffered saline (oxoid). An amount of $10 \mathrm{ml}$ of each compound was spotted onto the agar along the edge of the plate. In the center of the plate, $10 \mathrm{ml}$ of $60 \%$ ethanol (negative control) and $10 \mathrm{ml}$ of a carbose $(4 \mathrm{mg} / \mathrm{ml}$, SIGMA) were spotted side by side. Onto each spot, $10 \mathrm{ml}$ of pea shoot extract ( $\alpha$ Glucosidase) was added and left to digest for $10 \mathrm{~min} ; 1 \mathrm{ml}$ of iodine solution (UniLAB/Saarch, South Africa) was then poured over the surface of the plate and the excess discarded. Areas where the starch was digested by $\alpha-$ Glucosidase appeared clear in colour, indicating no inhibition of enzymatic activity. Spots which appeared blue due to iodine dying the undigested starch indicated the inhibition of $\alpha$-Glucosidase.

\section{In vitro studies with S. mansoni stock and working plant extract solutions}

In vitro schistosomicidal evaluation was conducted on cercariae evolutionary form. Stock solutions of extract, fractions and isolated compounds were prepared according to the procedure described previously ${ }^{24}$.

\section{Preparation of Cercariae Suspension}

Schistosome cercariae's were obtained from experimentally infected $B$. pfeifferis nails as previously described $^{24}$.

\section{In Vitro Cercaricidal Activity Test}

The effects of crude extract (extract code5), fractions (extracts codes 6, 7, 8) (FAF2, FAF4, FAF5) and isolated compounds FAF6 - FAF11 (extracts codes 9, 10 and 11) on Schistosoma infectious stage (cercariae) were assessed as previously ${ }^{24}$.

\section{Antimicrobial assay}

\section{Microorganisms and growth conditions}

C. albicans (Donated by Mr. M. Morobe, Department of Biological Sciences of the University of Botswana) were used as test organisms ${ }^{25}$ :

C. albicans Microorganisms was grown in nutrient Sabouraud Dextrose Broth (HiMedia, South Africa) at $32^{\circ} \mathrm{C}$ for $48 \mathrm{~h}$. Microorganisms were maintained on agar plates at $4^{\circ} \mathrm{C}$ or stored as glycerol stocks at $80^{\circ} \mathrm{C}$.

\section{Antimicrobial assays}

Sterile molten agar medium $(400 \mathrm{~mL}$ ) was pipetted into each well of a sterile 24-well culture plate (Corning) and left to solidify.

Yeast (C. albicans) were grown overnight in the irrespective media to a density of $1-106 \mathrm{cfu} / \mathrm{ml} .10 \mathrm{ml}$ of culture were pipettes onto each well of the agar plates. EtOH (60\% aqueous solution, B\&M, Scientific, Cape Town, South Africa) was the negative control across all antimicrobial assays. The positive controls were and penicillin/Streptomycin/fungizone (PSF, 100x; Highveld Biological, South Africa). $10 \mathrm{ml}$ of EtOH, antibiotic, or compound were pipetted onto the surface of the agar in duplicate wells. The plates were later inverted and incubated in a moist chamber. Inhibition was indicated by a clear area on the agar surface, while visible growth of colonies indicated inhibition, poor/very poor/no inhibition.

\section{RESULTS AND DISCUSSION}

\section{Fractionation and Isolation of Compounds Using Column Chromatography}

In this study, the phytochemical composition of crude Faidherbia albida (Mimosaceae) roots and leaves extracts and fractions from methylene chloride/methanol (1v, 1v), n-hexane, and ethyl acetate solvents, afforded 14 compounds for the first time by silica gel column chromatography and identified as $3 \beta$-Friedelinol ${ }^{26}$ (1), Friedelan-3-one ${ }^{27}(2)$, Heptadecanoic acid ${ }^{28}(3)$, Ergosterol$\beta$-D-glucoside 29 (4), $\quad(3 R, 4 R, 5 S, 6 R)-2$-(hydroxymethyl)-6$(4,4 a, 6 b, 8 a, 11,11,12 b, 14 a-o c t a m e t h y l-d o c o s a h y d r o p i c e n-$ 3-yloxy)-tetrahydro-2H-pyran-3,4,5-triol ${ }^{30}$ Brassicasterol Benzoate ${ }^{31}(6)$, Kaempferol ${ }^{32}$ (7), TransTiliroside $^{33}(8)$, Lupeol $^{33-34}(9)$, Betulin $^{27}(10)$, Maslinic acid ${ }^{27}$ (11), Oleanolic $\operatorname{acid}^{35}$ (12), Quercetin-3-O- $\alpha$ rhamnoside $^{30}(13)$ and Apigenin ${ }^{30}(14)$. The structures of the compounds were determined by analysis of their NMR data and comparison with those reported in the literature (Figure 1). 

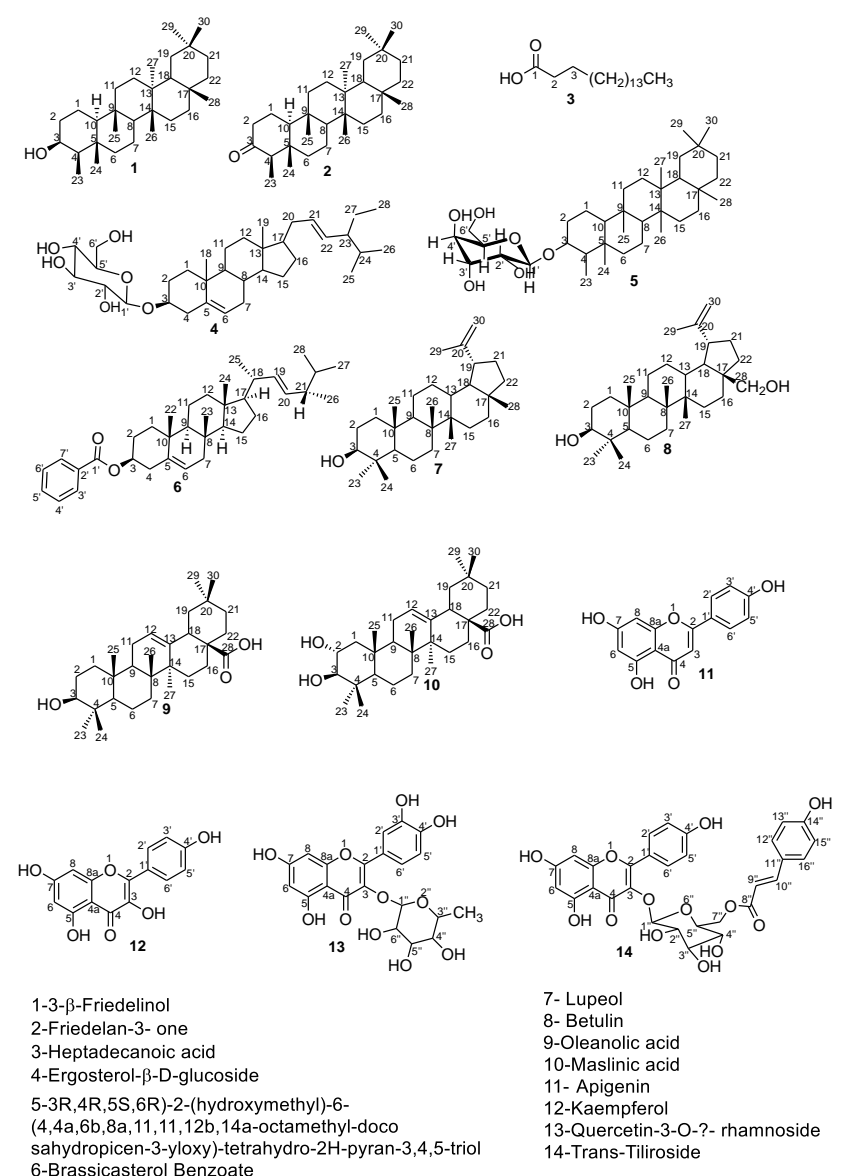

1-3- $\beta$-Friedelinol

2-Friedelan-3- one

3-Heptadecanoic acid

4-Ergosterol- $\beta$-D-glucoside

$5-3 R, 4 R, 5 S, 6 R)-2-($ hydroxymethyl)-6-

(4,4a,6b,8a, 11,11,12b, 14a-octamethyl-doco
sahydropicen-3-yloxy)-tetrahydro-2H-pyran-3,4,5-trio

6-Brassicasterol Benzoate

Figure 1: Structures of compounds isolated from Faidherbia albida (Mimosaceae)

Among these phytochemicals, Trans-Tiliroside (14) and $3 \beta$ Friedelinol (1) were found to be the majority compounds.
The first, a Triterpenes type is found in both ethyl acetate fractions, but approximately two times more present in roots than in leaves; whereas, the second, Flavonoids were found only in $n$-hexane fraction of roots. The result corresponds to the report in the literature that different solvent extraction and geographical area may result in obtaining different phytochemical constituents ${ }^{36}$.

In an attempt to characterize their bioactivities, isolated compounds and various extracts, fractions were investigated for their antioxidant potential, anthelmintic and antifungal effects against Schistosoma mansoni and Candida albicans respectively, $\alpha$-Glucosidal and Trypsin activity.

Cercaricidal activity of crude roots and Leaves extracts, fractions and the compounds (13)

Schistosomiasis is a chronic and debilitating disease caused by a trematode of the genus Schistosoma and affects over 207 million people ${ }^{36}$. Chemotherapy is the only immediate recourse for minimizing the prevalence of this disease and involves predominately the administration of a single drug, praziquantel (PZQ). Although PZQ has proven efficacy, there is a recognized need to develop new drugs as schistosomicidal since studies have shown that repeated use of this drug in areas of endemicity may cause a temporary reduction in susceptibility in isolates of Schistosoma mansoni ${ }^{36}$.

The kinetics of mortality of the cercariae of $S$. mansoni after exposure to the crude extract, fractions and the compounds from Faidherbia albida are presented in figure 2: A-F.

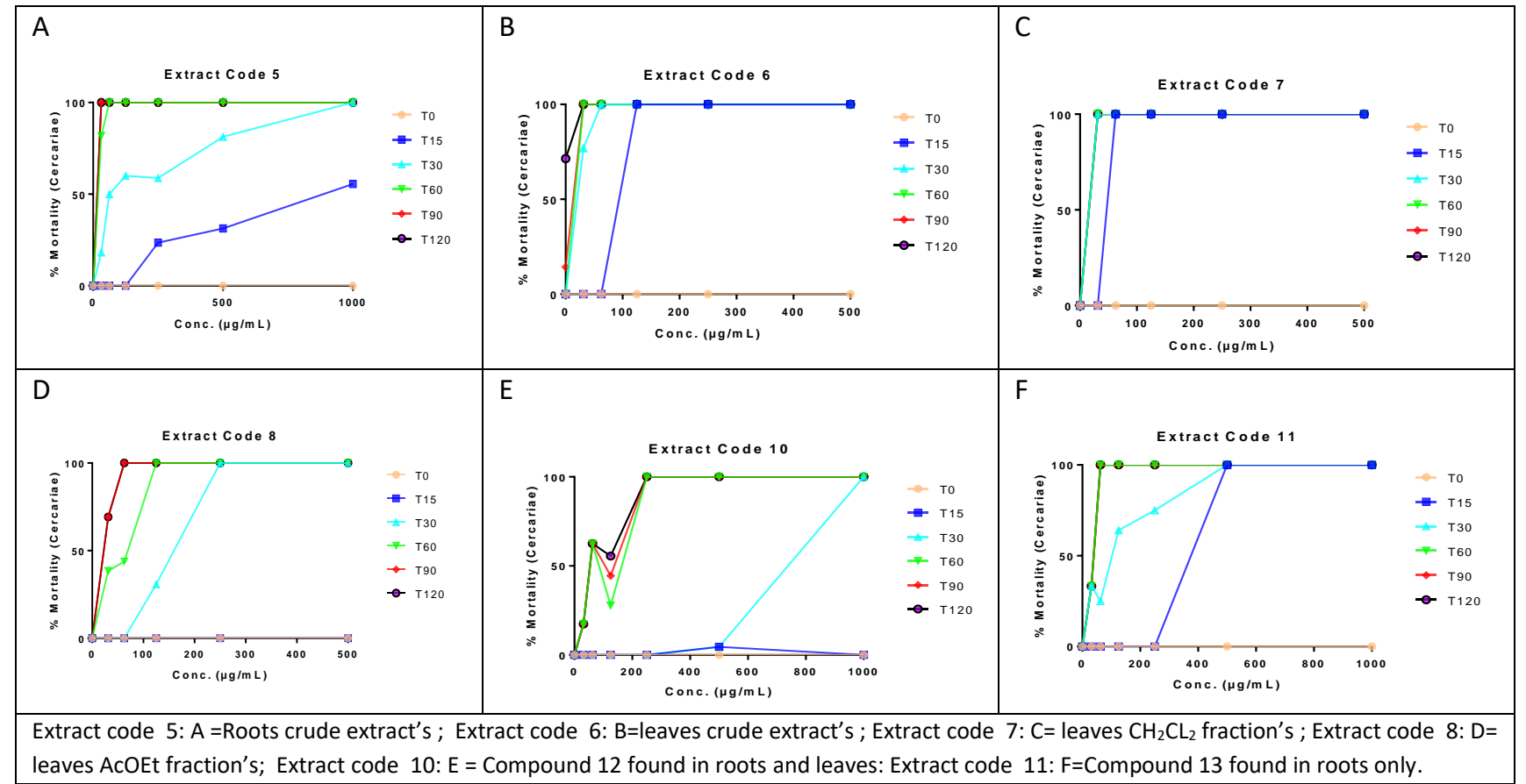

Figure 2: Kinetics of mortality of the cercariae of $S$. mansoni after exposure to the crude extracts, fractions and the compounds from Faidherbia albida 
The results indicate that cercariae death occur in a dosedependent manner for all extracts. The beginning of death begins after $15 \mathrm{~min}$ of exposition of the cercariae (Figure 2: A, D, E, F). With the concentration of $31.25 \mu \mathrm{g} / \mathrm{ml}$ of the extracts codes 5, 6 and 7, all the cercariae dead after 30, 60 and 90 min for extracts codes $C, B$ and $A$ respectively (Figure 2: $A, B, C$ ). On the other hand, one notes a death rate of $100 \%$ after $30 \mathrm{~min}$ when cercariae are exposed to each sample at $1000 \mu \mathrm{g} / \mathrm{ml}$. In low concentrations (31.25, 62.5, and $125 \mu \mathrm{g} / \mathrm{ml}$ ) some cercariae survived after respective time's intervals of 90 and 120 min, respectively (Figures 2: $D, E, F)$. An increase in the mortality rate of the cercariae for 15, 30, 60, 90, 120 and 150 min (Figures 2: A, B, C, D, F) were observed.

Roots crude extract's caused $100 \%$ cercariae death after 90 min at low concentration $31.25 \mu \mathrm{g} / \mathrm{ml}$, less than $50 \mu \mathrm{g} / \mathrm{ml}$, while leaves EtOAc fraction's, although was more active than leaves crude extract's, however none of them caused $100 \%$ death. Comparing the effect of different concentrations of the crude extracts, fractions and isolated compounds on the $S$. mansoni cercariae mortality clearly shows that leaves $\mathrm{CH}_{2} \mathrm{CL}_{2}$ fraction's is the most active, seconded by the isolated compound 13 from roots. This might strongly indicate and justify synergistic effects of the chemical constituent's presents in these samples.
Previous works done by Gouveia in 2018 showed that Flavonoids were able to form complexes with cholesterol and decreased its level in plasma and increased cholinesterase activity or may be decreased the frequency of cardiac contraction and additionally, they are thus regarded as privileged structures used for a broad spectrum of activities and are potential candidates for sources of new drug prototypes ${ }^{37}$. Here, the Flavonoid compound (13) is the most active component, making Faidherbia albida a potential source of drugs for the fight against schistosomiasis. The exposure of the S. mansoni cercariae to crude extract, fractions and compounds showed that the plant have larvicidal activities against S. mansoni larvae.

Antioxidant, $\alpha$-glucosidase and trypsin activities, $\alpha$ glucosidase and trypsin inhibiton and antifungal activities against candida albicans strain of crude roots and leaves extracts, fractions and the compounds (13)

The results of antioxidant, $\alpha$-Glucosidase and trypsin activities, antifungal activities against Candida albicans strain, as well as of $\alpha$-Glucosidase and Trypsin inhibition of compounds, extracts and fractions of roots and leaves of Faidherbia albida, are reported in Table 1.

Table 1: Antioxidant, $\alpha$-Glucosidase and Trypsin activities/inhibition of compounds, fractions and extracts from roots and Leaves of Faidherbia albida

\begin{tabular}{|l|c|c|c|c|c|c|}
\hline Sample & $\begin{array}{c}\text { Candida } \\
\text { albicans }\end{array}$ & $\begin{array}{c}\text { Glucosidase } \\
\text { activity }\end{array}$ & $\begin{array}{c}\text { Glucosidase } \\
\text { inhibition }\end{array}$ & $\begin{array}{c}\text { Trypsin } \\
\text { activity }\end{array}$ & $\begin{array}{c}\text { Trypsin } \\
\text { inhibition }\end{array}$ & Antioxidant \\
\hline Crude roots extract & 1 & $\mathbf{3}$ & 0 & 0 & 0 & $\mathbf{3}$ \\
\hline Crude leaves extract & 1 & $\mathbf{3}$ & 0 & 0 & 0 & 3 \\
\hline EA roots fraction & 2 & $\mathbf{3}$ & 1 & 0 & 0 & 3 \\
\hline EA leaves fraction & 2 & 0 & 2 & 0 & 0 & 3 \\
\hline Compound 13 & 0 & 1 & $\mathbf{3}$ & 0 & 3 & 0 \\
\hline
\end{tabular}

$\mathbf{3}=$ active, $\mathbf{2}=$ weak activity, $\mathbf{1}=$ very weak activity, $\mathbf{0}=$ not active, $\mathbf{N E}=$ not enough material for test, $\mathrm{EA}=$ =thyl acetate

In this table 1, all the extracts and ethyl acetate fractions are active on both free radical scavenging by DPPH assay and enzyme $\alpha$-Glucosidase inhibition. Whereas the ethyl acetate fraction of the leave is active only on free radical scavenging by DPPH assay. The compound 13 on is active at the same time on $\alpha$-Glucosidase inhibition, Trypsin inhibition.

The use of antioxidants against schistosomiasis have been reviewed ${ }^{38}$. Works done by Gharib B. et al. in $1999^{39}$ showed that oxidative processes triggered by liberation of reactive oxygen species (ROS) resulting from the immunological response and disturbance in cellular antioxidant homeostasis of affected organs during schistosomiasis; this could be due to the physiological properties of antioxidants, which are considered pharmacologically safe agents with minimal side effects ${ }^{16-17}$. Here, we showed all the extracts are active on free radical scavenging by DPPH Assay and the cercariae of S. mansoni, which reduce the combination of multiple biological active agent (multitherapy) therapy in favor of multitarget drug strategies.

The rationale for the evaluation of anti-oxidant and $\alpha$ Glucosidase inhibitory properties is explained by the works done by Nkengfack et al. in $2012^{40}$, revealing that antioxidants play a vital role in the immune system by reducing oxidative stress. Oxidative stress is, for example, induced by excess production of reactive oxygen species (ROS) due to HIV infection, while those realized by Sandstrom et al. in $1998^{41}$ were showed that an imbalance of cellular oxidant/antioxidant status may, vice versa, stimulate HIV replication. $\alpha$-Glucosidase inhibitors have attracted interest as potential therapeutic agents against diabetes type $2^{42}$ and as suppressors of the HIV replication cycle acting at the entry stage ${ }^{43}$. In contrast, the isolated compounds 13 didn't exhibit anti-oxidant activities. This absence of activity is due to the sugar moiety carried by the compound. In fact, Isoflavone without sugar moiety compounds are known to be among the best natural antioxidant, with the instar of 
Seputheisoflavone $\left(E_{50}=0.195 \mathrm{mg} / \mathrm{ml}\right)$ isolated from Ptycholobium contortum (N.E.Br.) Brummitt (Leguminosae) by Fotso et al. in $2015^{25}$, in comparison, ascorbic acid, which was used as reference drug. However, All the extracts (roots and leaves), as well as the ethyl acetate fraction of the roots were shown exhibited both anti-oxidant and $\alpha$-Glucosidase activities respectively, while the ethyl acetate leave fraction exhibited only anti-oxidant activity. Interestingly, the compound Quercetin-3-O- $\alpha$ - rhamnoside (13) is active at the same time on $\alpha$-Glucosidase inhibition, Trypsin inhibition and cercariae of Schistosoma mansoni, clarifying a possible candidate for multitarget drugs, although his antischistosomal against adult's worm were revealed by Xiao et al. in $2014^{44}$.

Susceptibilities of Candida albicans choose amongst Mycobacterium sp., which are the two major opportunistic pathogens occurring in an HIV/AIDS context, against extracts fractions and compounds 13 were also determined these samples were investigated. Up to $90 \%$ of HIVinfected individuals suffer from at least one episode of candidiasis, which is commonly characterized by oral thrush $^{45}$. Although we could show that 2 mediates fungicidal activity of both fractions, their values are rather high for both extract, none of isolated compounds were active against yeasts. Therefore, the antifungal activity can be considered as weak.

\section{CONCLUSION}

Faidherbia albida is a Cameroonian medicinal plants used for the treatment of skin diseases, wounds, fever, rheumatism, malaria and/or infectious diseases. This plant species is rich sources of compounds that can play an important role in the human health, in the broader context, in the treatment of various diseases, such as helminthes, diabetes type 2, schistosomiasis and antioxidant-related ailments and The synergic effect of the extract and fraction, and also their triple of Quercetin-3-O- $\alpha$ - rhamnoside (13) could classified Faidherbia albida among the potential candidate for the development of multitarget drugs. This could reduce the combination of multiple biological active agent (multitherapy) therapy in favor of multitarget drug strategies.

Acknowledgement: The authors would like to thank the University of Yaoundé I for supporting this work, and the Ministry of Higher Education of Cameroon for providing financial assistance to some authors through its Research and Innovation Special Funds. They are also grateful to Dr. Frederic Nana for the NMR analysis and the Botanist, Dr Frumsia for the collection and the identification of the plant material.

\section{REFERENCES}

1. Tchebemou BB, Nganso DYO, Soh D, Zondegoumba Nkwengoua. TE, Toghueo KRM, Sidjui SL, Fekam BF, Schneider B, Nyasse B. Chemical Constituents of Dissotis perkinsiae (Melastomaceae) and their Antimicrobial Activity. J Appl Pharm Sci, 6(08), 2016, 096-10.

2. Giffard PL, L’arbre dans le paysage Sénégalais: Sylviculture en zone tropicale sèche, Tome 1 CTFT Dakar, 1971, 43PP.
3. Ross JH. Acacia albida Del. in Africa. Boletin de Sociedade Broteriana, 2(40), 1966, 187-205.

4. Hutchinson J, Dalziel JM, Bora of West Tropical Africa, 2nd ed., Vol. 1, Part II. (Revised by Keay, R W J.), London, UK: Crown Agents for Overseas Governments and Administrations, 1958, 449P.

5. Vandenbeldt RJ, Faidherbia albida in the West African semi-arid tropics. Vandenbeldt, RJ Ed., Proceedings of a workshop, 22-26 April, 1991, Niamey, Niger, ICRISAT and ICRAF, Patancheru, A. P. 502324, India, 9-17.

6. Von Maydell H U, Arbres et arbustes du Sahel, leurs caractéristiques et leurs utilisations, GTZ, 1983, 53P.

7. Payne WA, Williams JH, MaiMoussa KA and Stern RD. Crop diversification in the Sahel through use of environmental changes near Faidherbia albida (Del). A. chev. Crop Sci., 38(6), 1998, 15851591.

8. Wickens GE, Seif El Din AG, Guinko S, Ibrahim N., Role of Acacia species in the rural economy of dry Africa and the near East. FAOconservation guide, 1995, 27P.

9. Muhammad S, Mushtaq A and Ashfaq A. Chemistry of the medicinal plants of the genus Acacia. Hamdard-medicus, 4(1), 1998, 63-67.

10. Gill LS, Medicinal uses of trees and plants in Africa, University of Benin Press, Benin, Nigeria, 1999, PP. 27.

11. Murunda CT, Use of seed of Faidherbia albida (syn. Acacia albida) for human consumption during famine periods in the Gokwe communal lands of Zimbabwe, Australian dry zone Acacias for human food, CSIRO, Canberra, Australia, 1992, 93-98.

12. Timberlake J, Field guide to the Acacias of Zimbabwe, Publishing, Harare, 1990, PP.160.

13. Kubmarawa D, Ajoku GA, Enwerem NM and Okorie DA. Preliminary phytochemical and antimicrobial screening of 50 medicinal plants from Nigeria. Afr. J. Biotech, 6(14), 2007, 1690 - 1696.

14. Osuntokun OT, Olajubu FA. Comparative study of phytochemical and proximate analysis of seven Nigerian medicinal plants. Annual Review of Biomedical Sciences, 1(2354-25787), 2014, 67-68.

15. Tijani AY, Uguru MO and Salawu OA. Antipyretic, anti-inflammatory and anti-diarrhoeal properties of Faidherbia albida in rats. Afr. J. Biotech, 7(6), 2008, 696- 700.

16. Tijani AY, Uguru MO, Salawu OA, Abubakar A, Onyekwelu NO and Akingbasote JA. Effect of Faidherbia albida on biochemical parameters of rats infected with Trypanosoma brucei brucei. Afr. J. Pharm Pharmacol, 3(1), 2009, 26-30.

17. Salisu Y, Agunu A, Abubakar MS and Ibrahim G. Hypoglycemic effects of Acacia albida del. (Mimosaceae) methanolic root bark extract. Nig. J. Pharm. Sci, 8(1), 2009, 66 - 67 .

18. Salawu O, Tijani, AB, Nwaeze AA and Agbakwuru A. Antimalaria activity of ethanolic stem bark of Faidherbia albida (Del.) a. Chev (Mimosidae) in mice. Scholars Research Library Archives of Applied Sci. Res., 2(5), 2010, 261-268.

19. Calvalho LH, Brandao MGL, Santos-Filho D, Lopes JLC and Krettli AU (). Antimalarial activity of crude extracts from Brazilian plants studied in-vivo in Plasmodium bergheiinfected mice and in-vitro against Plasmodium falciparum in culture. Braz. J. Med. and Biol. Res, 24(11), 1991, 1113-1123.

20. Bazie S, Ayalew A and Woldetsadik K. Antifungal activity of some plant extracts against Colletotrichum musae the cause of postharvest banana Anthracnose. J. Plant Pathol. \& Microbiol, 5, 2014, 2-6.

21. Umar I, Mamman A. Nematicidal potential of Faidherbia albida fruit against Meloidogyne javanica on cowpea. Pak. J. Nematol, 32(1), 2014, 77-83.

22. Ogunbinu AO, Okeniyi S, Flamini G, Cioni PL, Ogunwande IA and Babalola IT. Essential oil composition of Acacia nilotica Linn and 
Acacia albida Delile (Leguminosae) from Nigeria. J. Essential Oil Res., 22(6), 2010, 540-542.

23. Fadipe A.L, Mann A, Dasaba VDO. Usman and P. Olajide. Isolation of some non-polar constituents from the fruits of Faidherbia albida (Del.) A. Chev. International journal of advances in pharmacy, biology and chemistry, 4(4), 2015, 2277-4688.

24. Fotso WG, Maher FA., Ngnintedo D, Ango PY, Kapche DGFW, Ngameni B , Ngwenya B, Yeboah SO, Ngadjui BT, Kerstin A-M. Three new isoFlavonoids properties from Ptycholobium contortum (N.E.Br.) Brummitt (Leguminosae). Phytochemistry Letters, 14, 2015, 254-259.

25. Tekwu EM, Bosompem KM, Anyan WK, Appiah-Opong R, BaffourAwuah OK, Tettey MD, Kissi FA, Appiah AA, Penlap Beng V,, Nyarko $\mathrm{K}$. In vitro assessment of Anthelmintic activities of Rauwolfia vomitoria (Apocynaceae) stem bark and roots against parasitic stages of Schistosoma mansoni and cytotoxic study". J. Parasitol. Res, 2017, 1-11.

26. Salazar GCM, Silva GDF, Duarte LP, Vieira-Filho SA, Lula IS. Two epimeric friedelane triterpenes isolated from Maytenus truncato Reiss: $1 \mathrm{H}$ and $13 \mathrm{C}$ chemical shift assignments. Magn Reson Chem, $38,2000,977-980$

27. Mahato SB, Kundu AP. ${ }^{13} \mathrm{C}$ NMR spectra of pentacyclic triterpenoids A compilation and some salient features. Phytochemistry, 37, 1994, 1517-1575.

28. Luo Y, Liu Y, Qi H, Wu Z, Zhang G. Steryl esters and phenylethano esters from Syringa komarowii. Steroids, 71, 2006, 700-705.

29. Backhouse C, Delporte R. Negrete SA. San Feliciano J, Lopez-Perez. Bioactive phenolic derivatives from Acaena splendens methanol extract, Phytotherapy Research, 16, 2002, 562-566.

30. Clark-Lewis JW \& Dainis I. Flavane derivatives: A new glycoside and other extractives from Acacia ixiophylla: Rhamnitrin (rhamnetin-3 $\alpha$ L-rhamnoside). Australian Journal of Chemistry, 21(2), 1968, 425 437.

31. Sissi HI, Ansari MA. \& Negoumy SI. Phenolics of Acacia farnesiana. Phytochemistry, 12(9), 1973, 2303

32. Jangade NM, Nagargoje PB \& Shirote JP. Isolation, phytochemical and biological evaluation of Acacia nilotica (L) willd. Leaf extract. International Journal of Pharmacognosy and Phytochemical Research, 6(2), 2014, 179-182.

33. Pedernera AM, Guardia T, Calderon CEG, Rotelli AE, de la Rocha NE, Saad JR, Verrilli MA, Aseff SG \& Pelzer LE. Anti-inflammatory effect of Acacia visco extracts in animal models. Inflammopharmacology, 18(5), 2010, 253-260.
34. Seo Y, Hoch J, Abdel-Kader M, Malone S, Derveld I., Adams H \& Kingston DGI. Bioactive Saponins from Acacia tenuifolia from the Suriname Rainforest1. J Nat Prod, 65(2), 2002, 170-174.

35. Akesa TM. Phytotaxonomy and phytochemicals of eight species of the Family Moraceae in Benue State, Nigeria. International Journal of Scientific \& Engineering Research, 7(2), 2016, 588-595.

36. NKwengoua ZTN, Tankoua WLD, Tekwu EM, Ndogo OE, Santos. A de Araujo R, Vidari G, Yan L, Shihong L, Shenghong L, Mendonça Junior FJB., Scotti L, Scotti MT, do Carma A. de Lima M, Nyasse B. Cytotoxic and Schistosomidal Activities of Extract, Fractions and Isolated Compounds from Zanthoxylum leprieurii (Rutaceae). Intenational Journal of Science: Base applied Research, 44(1), 2019, 209-222.

37. Gouveia M.J, Brindley P.J, Gärtner F, Correia da Costa J.M, Vale N. Drug repurposing for schistosomiasis: Combination of drugs or biomolecules. Pharmaceuticals, 2018; 11-15.

38. Maizels RM, Bundy DA, Selkirk M.E, Smith DF, Anderson RM. Immunological modulation and evasion by helminth parasites in human populaetions. Nature, 365, 1993, 797-805

39. Gharib B, Abd-Allah DM, Dessein H, De Reggi M. Development of eosinophil peroxidase activity and concomitant alteration of the antioxidant defenses in the liver of mice infected with Schistosoma mansoni. J. Hepatol., 30, 1999, 594-602.

40. Nkengfack GN, Torimiro JN, Englert H. Effects of antioxidants on CD4 and viral load in HIV-infected women in sub-Saharan Africadietary supplements vs. local diet. Int. J. Vitam. Nutr. Res., 82, 2012, 63-72.

41. Sandstrom PA, Muiray J, Folics TM, Diamon AM (1998). Antioxydant defenses influence HLV-1 replication and associated cythopathic effects. Free Radic Biol Medal, 24, 2009, 1485-1491.

42. Tundis R, Loizzo MR, Menichini F. Natural products as alphaamylase and alpha-glucosidase inhibitors and their hypoglycaemic potential in the treatment of diabetes: an update. Mini Rev. Med. Chem., 10, 2010, 315-331.

43. Robina I, Moreno-Varga A, Carmona AT, Vogel P. Glucosidase inhibitors as potential HIV entry inhibitors? Curr. Drug. Metab., 5, 2004, 329-361.

44. Xiao CJ, Zhang Y, Qiu L, Vu W, Zhao MZ, Dong X, Jiang B. Schistosomicidal and antioxidant flavonoids from Astragalus englerianus. Planta Med., 80(18), 2014, 1727-1731.

45. Runyoro DKB, Ngassapa OD, Matee MIN, Joseph CC, Moshi MJ. Medicinal plants used by Tanzanian traditional healers in the management of Candida albicans infections. J. Ethnopharmacol., 106, 2006, 158-165.

\section{Source of Support: None declared.}

Conflict of Interest: None declared.

For any question relates to this article, please reach us at: editor@globalresearchonline.net New manuscripts for publication can be submitted at: submit@globalresearchonline.net and submit_ijpsrr@rediffmail.com 